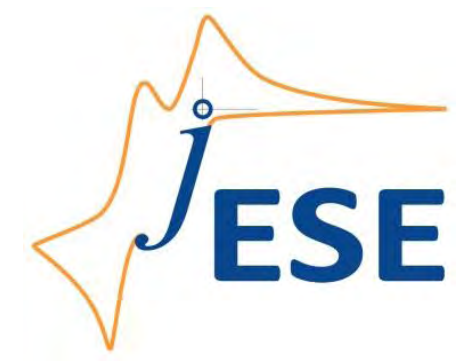

Open Access: ISSN 1847-9286

www.jESE-online.org

Original scientific paper

\title{
Ir-Ni oxide as a promising material for nerve and brain stimulating electrodes
}

\author{
Joan Stilling ${ }^{\bowtie}$, Nehar Ullah and Sasha Omanovic \\ Department of Chemical Engineering, McGill University, 3610 University Street, Montreal, Quebec, \\ Canada, H3A OC5
}

${ }^{\otimes}$ Corresponding author: E-mail: joan.stilling@mail.mcgill.ca; Tel.: +1-587-894-0660;

Fax: +1-514-398-6678

Received: August 11, 2014; Published: September 22, 2014

\begin{abstract}
Tremendous potential for successful medical device development lies in both electrical stimulation therapies and neuronal prosthetic devices, which can be utilized in an extensive number of neurological disorders. These technologies rely on the successful electrical stimulation of biological tissue (i.e. neurons) through the use of electrodes. However, this technology faces the principal problem of poor stimulus selectivity due to the currently available electrode's large size relative to its targeted population of neurons. Irreversible damage to both the stimulated tissue and electrode are limiting factors in miniaturization of this technology, as charge density increases with decreasing electrode size. In an attempt to find an equilibrium between these two opposing constraints (electrode size and charge density), the objective of this work was to develop a novel iridium-nickel oxide ( $\left(r_{0.2}-N_{0.8}\right.$-oxide) coating that could intrinsically offer high charge storage capacity. Thermal decomposition was used to fabricate titanium oxide, iridium oxide, nickel oxide, and bimetallic iridium-nickel oxide coatings on titanium electrode substrates. The $\mathrm{Ir}_{0.2}-\mathrm{Ni}_{0.8}$-oxide coating yielded the highest intrinsic (material property) and extrinsic (material property + surface area) charge storage capacity (CSC) among the investigated materials, exceeding the performance of the current state-ofthe-art neural stimulating electrode, Ir-oxide. This indicates that the $1 r_{0.2}-\mathrm{Ni}_{0.8}$-oxide material is a promising alternative to currently used Ir-oxide, Pt, Au and carbon-based stimulating electrodes.
\end{abstract}

\section{Keywords}

Neural stimulation electrodes; metal oxides; iridium; nickel; charge storage capacity 


\section{Introduction}

With a recently emerging focus on the development of neural prostheses (technology which is able to interact with the body's nervous system) to the utilization of electrical stimulation as a therapy for various neurological disorders, many efforts have been directed towards overcoming the extensive challenges related to electrical stimulation electrode design. Controlled and selective stimulation of the human's central and/or peripheral nervous system is the key to success for all neural stimulation treatment techniques, including deep brain stimulation (DBS), functional electrical stimulation (FES), bladder, intraspinal and epidural stimulation. DBS is used as a treatment for Parkinson's disease, epilepsy, essential tremor, dystonia, and medication resistant psychiatric diseases such as obsessive compulsive disorder (OCD) and depression, while FES, bladder, and spinal stimulation are utilized in stroke, multiple sclerosis, and spinal cord injury rehabilitation therapy[1-6]. The immensely widespread applicability of electrical stimulation in treating numerous pathologies demonstrates its incredible utility in successful medical device development.

In all such applications, a neural electrode works as a bridge - transferring information between the external electronic control device and the human biological system (neurons) [7]. Neural prostheses based on stimulation and recording of neurons (i.e. the cells that transmit electrical information in the body) involve the use of electrodes, which are chronically interfaced to the nervous system. Recording electrodes typically pick up information from sensory systems whereas stimulating electrodes, which are the focus of this article, often communicate with motor systems. Metallic biomaterials have been the main material of choice for neural electrodes. For stimulation; titanium (Ti), titanium nitride (TiN), stainless steel (SS), platinum (Pt), Pt alloys, iridium (Ir), ruthenium ( $\mathrm{Ru})$, and rhodium (Rh), which support charge injection by capacitive and faradic mechanisms are available, while materials used for recording electrodes include stainless steel, PtIr alloys, Ir oxide and Ti-nitride [7, 8].

Implantation of neural stimulators in each clinical application requires a safe protocol of operation involving their size, charge injection, and service time [9-11]. However, there are many challenges related to the development of such devices. One of the key problems with current electrodes is their lack of stimulus selectivity, which occurs as a result of large electrode size relative to the targeted neuronal population. For this reason, desirable electrodes are characterized by having a small enough geometric size for targeted and selective neuronal activation, while still possessing the ability to inject a sufficient charge density that does not induce harmful effects on neural function, cell structure, or the electrode itself.

To address the issues mentioned above related to the neural stimulation electrodes, the biocompatibility properties of the material in response to stimulation can be investigated. Metallic biomaterials offer many advantages over the other materials, such as high mechanical strength, wear resistance, inertness, and potential to produce an oxide layer on the surface of the material. However, metallic biomaterials are vulnerable to irreversible faradaic reactions such as water electrolysis, corrosion and the release of toxic ions through gas evolution or metal dissolution $[10,12,13]$. The performance of the electrode depletes with time as a result of the constantly changing and aggressive environment prone to corrosion in which the electrode is implanted. All of these susceptibilities may induce an immune or necrotic response in adjacent tissue, which can lead to fouling of the electrode surface and loss of functionality [12-14]. Hence, a material with a relatively high corrosion resistance is a desirable feature for a stimulating electrode. It is also essential that the material has a high charge storage capacity; one that effectively stimulates an action potential in a nerve [15]. Various noble metals such as Pt and Pt/Ir alloys have a long history 
of use as neural electrodes. However, the maximum charge injection $\left(Q_{\text {inj }}\right)$ limit of $\mathrm{Pt}$ (100-300 $\mu \mathrm{C} \mathrm{cm}^{-2}$ geometrical area) is insufficient in most cases for nerve stimulation $[7,16,17]$. Titanium is also used extensively in the biomedical field and neuroscience research due to its high corrosion resistance, biocompatibility, low cost and non-toxicity [18-20]. However, its low charge injection capacity limits its use as a neural stimulation electrode material. Thus, faradaic electrode coatings based on films of Ir oxide have been developed in response to the need for microelectrodes with higher charge injection capacities. Activated iridium oxide film (AIROF) microelectrodes, prepared electrochemically, are widely used for neural applications as they offer a significant improvement in the charge injection limit $\left(2-3 \mathrm{mC} \mathrm{cm}^{-2}\right.$ geometrical area) with a reversible faradic reaction $\left(\mathrm{Ir}^{3+} \leftrightarrow \mathrm{Ir}^{4+}+\mathrm{e}^{-}\right)$when compared to other materials. However, activated iridium oxide delaminates under high current pulsing and deposits particles into the surrounding tissues. Additionally, the brittle mechanical properties of iridium oxide make it very difficult to fabricate microelectrodes [7,10,21-24].

New methods have been adopted to address this problem by combining other precursors like ruthenium, titanium, tantalum and tin with iridium to form mixed metal oxide films. However, the long-term stability and higher charge storage/injection of these coatings still needs to be optimized for better performance [8,21,25-28]. Some lower cost transition metal oxides such as nickel, manganese, cobalt and their composites have also been investigated as an alternative electrode material for neural stimulating electrode applications. Nickel for example, has comparable electrochemical behavior to iridium, is low in cost, and readily available. Yet, its nonbiocompatible structure, low corrosion resistance and low specific capacitance, limit the feasibility of using pure $\mathrm{Ni}$ as a neural electrode coating material $[12,29,30]$. Despite the drawbacks of pure nickel, it may be combined with other precursors (metals), such as iridium, to utilize its beneficial properties. The potential of bimetallic coatings such as this may help to solve some of the problems encountered with current electrodes.

As outlined above, there is an evident need for the investigation into new materials for neural stimulating electrodes. The aim of this study was to alter electrode surface characteristics through the development of a novel nickel-iridium bimetallic coating on a titanium substrate. In an effort to reduce the aforementioned problems, electrodes were thermally prepared, electrochemically tested, and results were compared with the current industry standard (state-of-the-art), iridium oxide coating (control).

\section{Experimental}

\section{Selection of electrode coating materials}

Various metal oxide coatings were deposited on a titanium substrate and then characterized using a number of different electrochemical and surface characterization techniques. A titanium plate (99.2\%, metal basis) was used as the substrate. Titanium was chosen due to its excellent biocompatibility characteristics, chemical stability, mechanical strength, and biocompatibility [31]. During experimentation, pure iridium oxide coatings were produced as a control sample; this is currently one of the most common materials applied to neural electrodes due to its high charge storage capacity when compared to other pure metals. However, this stimulating electrode suffers from a number of drawbacks, including loss of the charge-injection capability with time, delamination of the oxide coating, fouling, and high cost [7,32].

To address these issues and develop a better stimulating neural electrode, alternative metals were investigated. Nickel was chosen on an empirical basis due to its stability and low cost [12]. In 
addition, other laboratories have previously demonstrated that this metal shows adequate electrochemical properties in terms of its redox and capacitive behavior, which are similar to that of iridium. Both a one hundred percent nickel oxide coating and an uncoated titanium electrode substrate were created as additional controls for experimentation.

In an attempt to obtain a coating that performs superior to both the pure nickel and iridium oxide in terms of coating stability and charge injection capability, an $\operatorname{Ir}_{0.2}-\mathrm{Ni}_{0.8}$-oxide coating was produced. This bimetallic coating combination of iridium with nickel is a novel idea for use in the application of neural electrodes.

\section{Electrode preparation}

Metal oxide coatings were formed through a thermal decomposition method on a flat titanium substrate (purity $99.2 \%$ metals basis, Alfa Aesar 10398). To coat the titanium plates, a $0.15 \mathrm{M}$ precursor solution was prepared by dissolving the corresponding metal precursor salts into isopropanol (purity 99.9\%, Fisher Scientific A416-1). $\mathrm{NiSO}_{4} \times 6 \mathrm{H}_{2} \mathrm{O}$ (Sigma Aldrich 227676) was the precursor used to prepare the nickel oxide coating and $\mathrm{IrCl}_{3} \times 3 \mathrm{H}_{2} \mathrm{O}$ (Acros Organics 195500050) was used for the iridium oxide coating. It was assumed that the molar ratio of the metals in the precursor solution gave the same molar ratio in the electrode coating.

Titanium substrates used in all experiments were $1 \mathrm{~cm}$-diameter discs with a thickness of $0.2 \mathrm{~cm}$. In order to create a surface to which the precursor solution could adhere, the substrate was polished and etched. The titanium substrate plate was first wet-polished using 600 -grit SiC sandpaper [33]. Then, the polished plate was rinsed thoroughly with abundant deionized water and sonicated for 30 minutes in a water bath to remove polishing residue. Next, the polished plate was etched in a boiling solution of hydrochloric acid (33 wt. \%, Fisher Scientific) and deionized water ( $1: 1$ by volume) for 30 minutes [34,35]. After etching, the plate was again thoroughly rinsed with deionized water and then dried in argon.

The metal precursor coating solution was applied uniformly on the freshly prepared titanium substrate with a paint brush. After applying the first coating, the sample was placed in an oven at $383 \mathrm{~K}$ for 5 minutes (in order to vaporize the solvent), followed by annealing of the sample at $737 \mathrm{~K}$ in a furnace for 15 minutes. The sample was then removed from the furnace and allowed to cool for 5 minutes before another coating was applied. The same procedure was repeated six times in order to form six coatings on the titanium substrate. Finally, the sample was annealed in the furnace at $737 \mathrm{~K}$ for a period of one hour to oxidize the coating [26,28,36-38].

\section{Electrochemical measurements}

A standard three-electrode electrochemical cell was employed in all electrochemical experiments. Both a graphite counter electrode and saturated calomel reference electrode (SCE) were utilized. All potentials in this paper are expressed with respect to SCE. A titanium plate coated by Ir-, $\mathrm{Ni}$ - or $\operatorname{Ir}_{0.2}-\mathrm{Ni}_{0.8}$-oxide was applied as the working electrode (only one side of the titanium plate was coated with the metal-oxide coating). To utilize the coated side of the working electrode samples during experimentation, a custom-made electrode holder was used to expose a $0.785 \mathrm{~cm}^{2}$ geometrical area of the working electrode to the supporting electrolyte. Electrochemical experiments were employed in an aqueous $0.16 \mathrm{M} \mathrm{NaCl}$ phosphate buffered solution at $\mathrm{pH}$ 7.4. The buffer solution, which is commonly used to simulate human-body fluids, was prepared by mixing appropriate amounts of sodium chloride (purity $\geq 99.5 \%$, Fluka Chemika 71381), sodium dihydrogen phosphate anhydrous (purity $99 \%$, Fluka Chemika 71496) and sodium phosphate dibasic (purity $99.5 \%$, Fisher Scientific S374). A $5 \mathrm{M} \mathrm{NaOH}$ solution (Fisher Scientific SS256) was 
used to adjust the $\mathrm{pH}$ of the buffer solution. In order to maintain an oxygen-free electrolyte, argon (99.998\% pure) was purged, both through the electrolyte 30 minutes prior to electrochemical measurements and during the electrochemical experiments. Electrochemical measurements were performed using an AUTOLAB potentiostat/galvanostat/FRA PGSTAT 30 controlled by FRA2 and GPES v. 4.9 software.

The general electrochemical behaviour and charge storage capacity of the uncoated Ti (control) electrode and the $\mathrm{Ir}$-, $\mathrm{Ni}$ - and $\mathrm{Ir}_{0.2}-\mathrm{Ni}_{0.8}$-oxide electrodes were determined using cyclic voltammetry (CV).

To ensure complete characterization of the surface processes occurring at the electrodesolution interface and in the oxide phase, electrochemical impedance spectroscopy (EIS) measurements were made in $0.16 \mathrm{M} \mathrm{NaCl}$ phosphate buffer solution over seven frequency decades, from $100 \mathrm{kHz}$ to $50 \mathrm{mHz}$. The alternating current (AC) voltage amplitude of $\pm 10 \mathrm{mV}$ was employed. The corresponding spectra were modeled employing the two equivalent electronic circuits (EEC) presented in Figure 1.

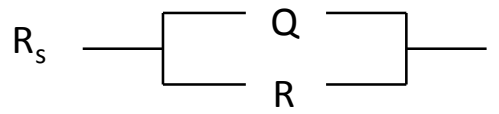

Figure 1. (a) Equivalent circuit model \#1

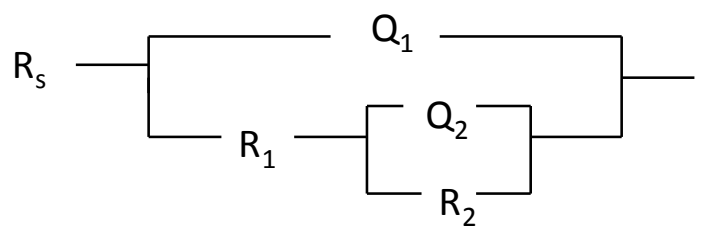

Figure 1. (b) Equivalent circuit model \#2

The values of solution resistance $\left(R_{\mathrm{s}}\right)$, polarization resistance or total resistance to charge transfer $\left(R=R_{1}+R_{2}\right.$ for circuit in Fig. $\left.1(\mathrm{~b})\right)$, and capacitance were determined by fitting the experimental data to either of the two models. A constant phase element (CPE), $Q$, was utilized instead of pure capacitance; this was due to the distribution of the relaxation times as a result of heterogeneities present at the micro level, such as surface roughness [39]. In Fig. 1(a), $Q$ represents the double-layer capacitance, while R represents the polarization resistance. In Fig. 2(b), $Q_{1}$ and $Q_{2}$ are the double-layer and pseudo-capacitance, respectively (the latter related to the redox transitions in the oxide phase). $R_{1}$ and $R_{2}$ are the electron-transfer and mass-transport resistance, respectively (the latter related to transport of protons in the oxide phase to balance the metal oxide charge change). The $\mathrm{Ir}_{0.2}-\mathrm{Ni}_{0.8}$-oxide coating was best modeled using the equivalent circuit element shown in Fig. 1(a), while the remaining coatings were modeled using the equivalent circuit model shown in Fig. 1(b).

\section{Surface morphology/topography}

Surface morphology/topography of the various metal coatings was investigated using a Phillips $\mathrm{XL}-30$ field emission scanning electron microscope (FE-SEM).

\section{Results and discussion}

\section{Surface characterization by scanning electron microscopy (SEM)}

In Figure 2, scanning electron micrographs of the three different coatings applied to the titanium substrate are shown. In Figure $2(\mathrm{a}, \mathrm{b})$, a highly roughened $\mathrm{Ir}_{0.2}-\mathrm{Ni}_{0.8}$-oxide coating can be observed. This is shown by its highly tortuous, inhomogeneous surface architecture. The iridium oxide coating shown in Figure 2(c,d) does not demonstrate as rough a surface as in Figure 2(a, b). The surface has deep cracks uniformly dispersed throughout the coating, as indicated by the thin black regions present throughout the image. This surface topography/morphology is less favorable 
than that in Figure 2(a, b), as less true surface area is available per geometric surface area to deliver charge. As a result, wider potential windows may be required to deliver a charge sufficient for neuronal stimulation. The nickel oxide coating shown in Figure 2(e, f) demonstrates slight cracks throughout surface. However, the troughs do not appear as deep and wide as those present in the iridium oxide coating shown in Figure 2(c, d). Further, the nickel oxide coating's small roughness value (lower true surface area) can be observed when compared to the $\mathrm{Ir}_{0.2}-\mathrm{Ni}_{0.8}$ oxide coating shown in Figure 2(a, b). Surface roughness has a strong effect on an electrode's charge storage capacity, which will be demonstrated and discussed later in the article.
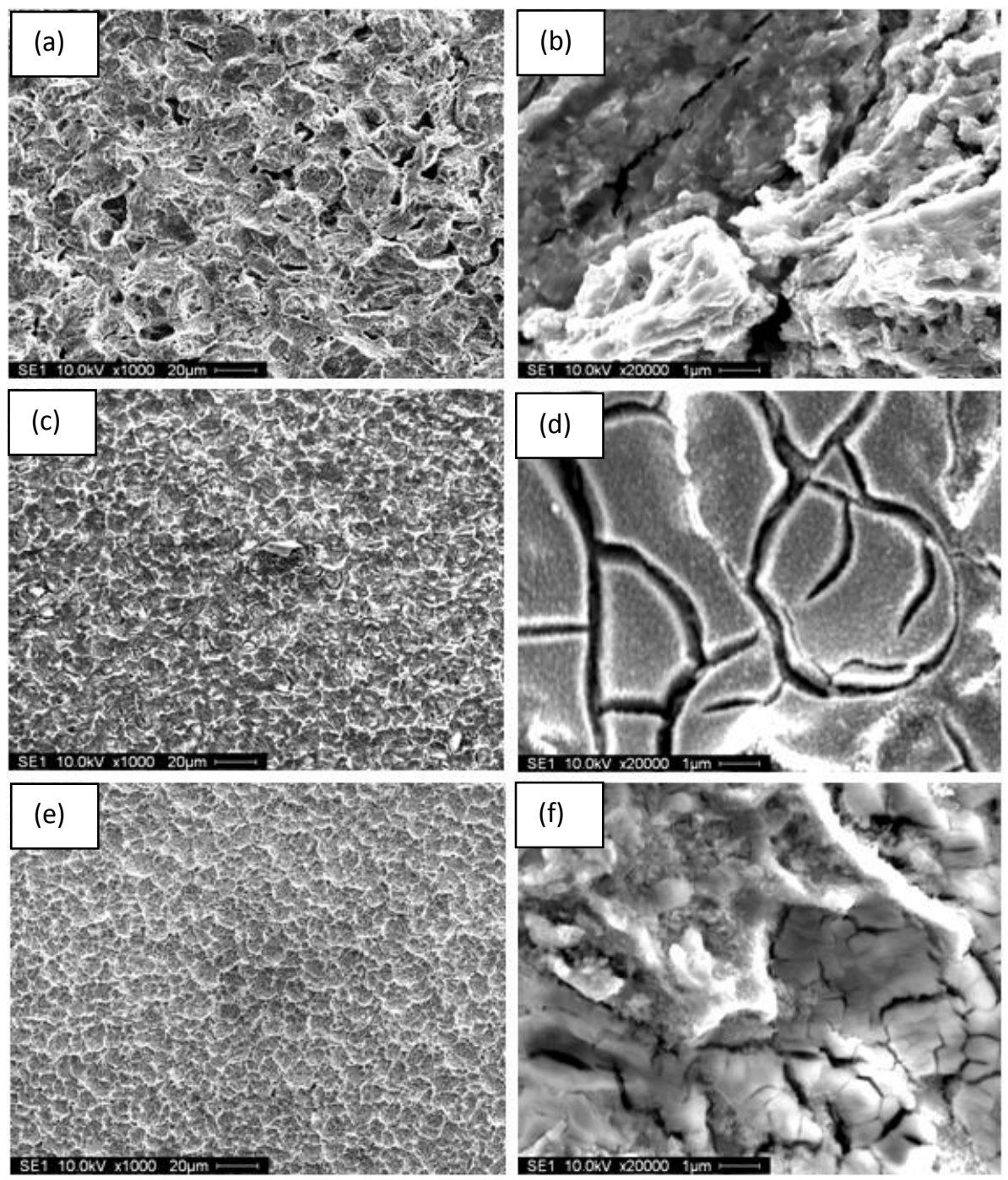

Figure 2. SEM micrographs of the metal oxide coatings formed on a Ti substrate after CV experiments in $0.16 \mathrm{M}$ saline phosphate buffer solution at $\mathrm{pH}=7.4$, $(\boldsymbol{a}, \boldsymbol{b}) \operatorname{Ir}_{0.2}-\mathrm{Ni}_{0.8}$-oxide $(\boldsymbol{c}, \boldsymbol{d})$ iridium oxide $(\boldsymbol{e}, \boldsymbol{f})$ nickel oxide.

\section{Electrochemical Characterization by Cyclic Voltammetry}

Cyclic voltammetry (CV) was used to assess the electrochemical redox behavior of the electrode coatings within the region between hydrogen and oxygen evolution; $-1.0 \mathrm{~V}$ to $1.0 \mathrm{~V}$. These measurements allowed for the characterization of the stimulation electrodes by their charge storage capacity (CSC). CSC is defined as the total amount of charge per unit geometric surface area (GSA), that may be stored reversibly in the electrode [13] and is sufficient enough to stimulate an action potential in a nerve without causing any damage to human tissues [7]. Hence, in order to investigate whether the developed coatings are capable of delivering sufficient amount 
of charge during stimulation, CSC of various coatings were determined using CV data presented in Figure 3. The presented behavior is typical of that displayed by purely capacitive and pseudocapacitive materials [7,17,40-43]. A few conclusions can be made by analyzing Figure 3 . First, there is a large difference in current response among the investigated materials; at a fixed potential, the recorded current increases in the order of $\mathrm{Ti}-<\mathrm{Ni}=\mathrm{Ir}<\mathrm{Ir}_{0.2}-\mathrm{Ni}_{0.8}$-oxide, indicating that the charge storage capacity behaves in the same manner. Second, when analyzing the $\operatorname{Ir}_{0.2}-\mathrm{Ni}_{0.8}$-oxide coating response, one can see that there are two redox peaks; an anodic peak at ca. $0.2 \mathrm{~V}$ and a cathodic peak at ca. $-0.1 \mathrm{~V}$. These peaks correspond to reversible redox transitions in the oxide phase, namely the $\operatorname{Ir}(\mathrm{III}) / \mathrm{Ir}(\mathrm{IV})$ and $\mathrm{Ni}(\mathrm{II}) / \mathrm{Ni}(\mathrm{IV})$ transitions [41-44]. These results demonstrate that the various electrode coatings behave quite differently when a charge is applied to the electrode.

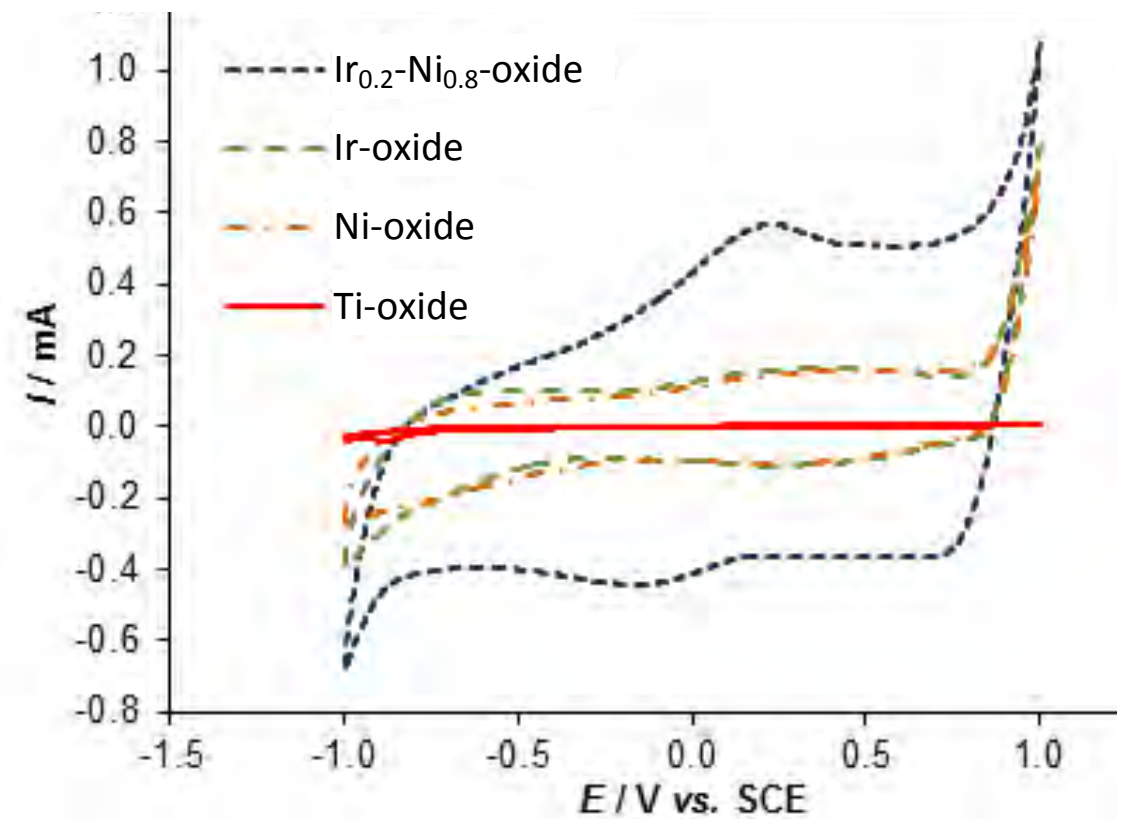

Figure 3. Cyclic voltammograms of $\mathrm{Ti}$-, $\mathrm{Ni}$-, Ir- and $\mathrm{Ir}_{0.2^{-}}-\mathrm{Ni}_{0.8}$-oxide coatings recorded in $0.16 \mathrm{M}$ saline phosphate buffer $\mathrm{pH}=7.4$ at a scan rate, $\mathrm{sr}=100 \mathrm{mV} \mathrm{s}^{-1}$.

To evaluate the amount of CSC that can be delivered during the anodic and cathodic polarization of the electrode, the corresponding anodic and cathodic areas under the curves were integrated and then normalized with respect to geometric surface area (GSA)in order to determine the extrinsic charge storage capacity $\left(\mathrm{CSC}_{\mathrm{Extrinsic}}\right)$. Figure 4, presents $\mathrm{CSC}_{\mathrm{Extrinsic}}$ of the various metal oxide coatings investigated. The $\operatorname{Ir}_{0.2}-\mathrm{Ni}_{0.8}$-oxide coating has the highest $\mathrm{CSC}_{\text {Extrinsic }}$ of all the materials tested, with a value of $30.3 \pm 4.8 \mathrm{mC} \mathrm{cm}$. Ir-oxide, which is the current state-of-the-art neural stimulation material, demonstrated a significantly lower $\mathrm{CSC}_{\text {Extrinsic }}$ than the bimetallic composite, yielding a value of $9.8 \pm 1.0 \mathrm{mC} \mathrm{cm}{ }^{-2}$. Pure Ni-oxide also failed to display high a CSC and restrained to a value of $2.8 \pm 1.1 \mathrm{mC} \mathrm{cm}^{-2}$, while the titanium (substrate) fell short of all other metal oxide coatings, exhibiting a CSC of only $0.23 \pm 0.07 \mathrm{mC} \mathrm{cm}$. The fact that the titanium oxide sample has a very low CSC value further indicates that adding a coating effectively increases the extrinsic CSC of the electrode. Additionally, it can be concluded that the data obtained from the samples with coatings are a result of the properties of the coating itself and not the titanium substrate. The highest extrinsic CSC of $\mathrm{Ir}_{0.2}-\mathrm{Ni}_{0.8}$-oxide coating is most likely due to its large surface roughness value (determined in current studies, but not shown here). The fairly low percent relative standard deviations for all of the samples in Figure 4 indicate that the coatings were able to store charge in a reproducible manner. To the best of authors' knowledge, a higher $\operatorname{CSC}_{\text {Extrinsic }}$ 
value has not been reported in the literature for Ir-Ni-oxide coatings under the experimental condition applied.

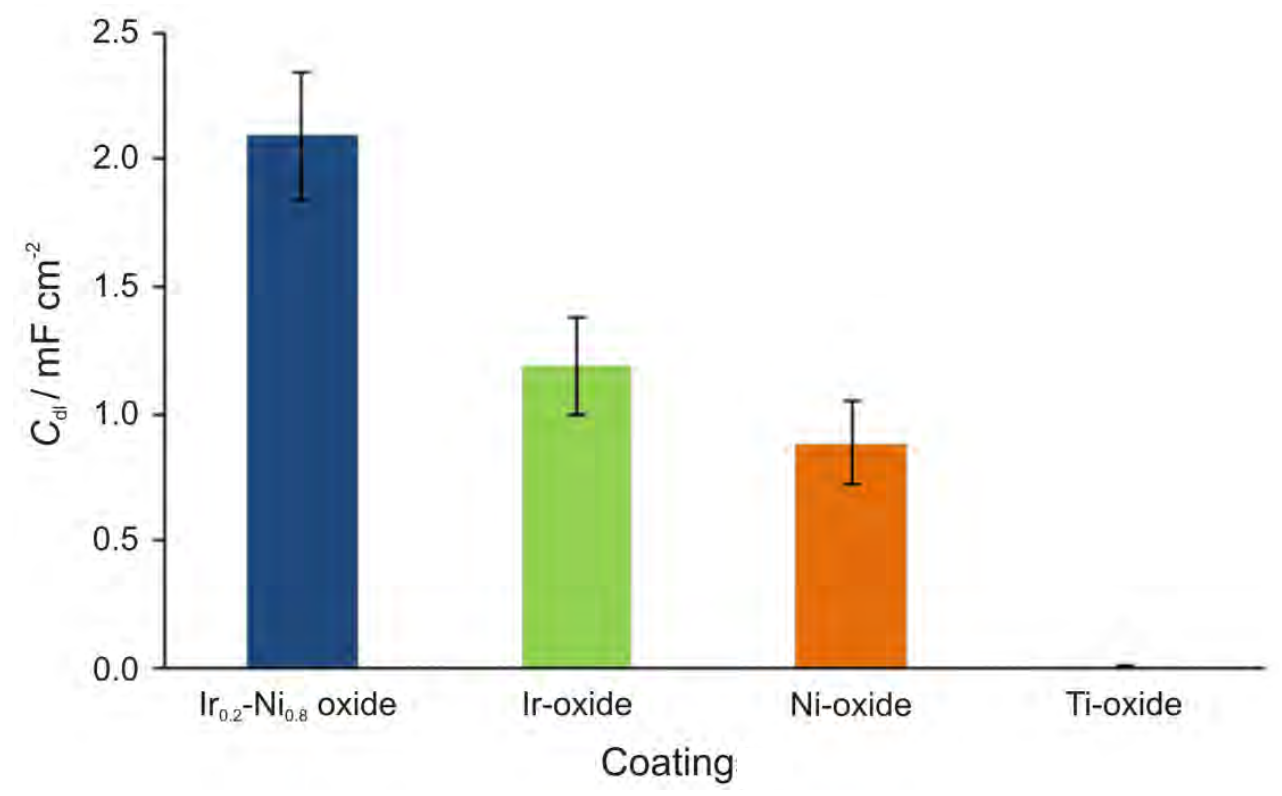

Figure 4. Total extrinsic charge storage capacity ( $\operatorname{CSC}_{\text {Extrinsic }}$ ) of various metal oxide coatings determined from CVs in Figure 3, for at least three sample (coating) replicates.

The error bars represent the corresponding standard deviation.

In order to investigate the charge storage capacity of the material alone (without considering the effect of surface area), the intrinsic charge storage capacity was further examined. For this purpose, a true electrode surface area was first determined form electrochemical impedance spectroscopy results.

\section{Characterization by Electrochemical Impedance Spectroscopy (EIS)}

Figure 5 represents an example of the EIS spectra obtained for $\operatorname{Ir}_{0.2}-\mathrm{Ni}_{0.8}$-oxide coating at the $0.5 \mathrm{~V}$. Similar EIS responses were obtained for all other oxide coatings, however they are not included in this analysis. To quantify the EIS result, the experimental spectrum presented in Figure 5 was modeled using non-linear least-squares fit analysis (NLLS) software [45] and the electrical equivalent circuit (EEC) presented in Figure 1(a). The modeled data are represented by the dashed line in Figure 5. It is evident that there is a substantial agreement between the experimental data (circles) and modeled data (dashed line), confirming the validity of the proposed EEC in describing the impedance behavior of the investigated system under the given experimental conditions. The same EIS analysis of the other developed metal oxide coatings was carried out, using the EEC in Figure 1(b). In order to determine the true electrode surface area of the metal oxide coatings, EEC parameters were analyzed for the contribution of double-layer capacitance.

Low impedance is required for the stimulation of neural networks. Since capacitance is inversely proportional to impedance, a large capacitance is desired [9]. To investigate the capacitive behavior of the developed coatings, a true value of the double-layer capacitance $\left(C_{\mathrm{dl}}\right)$ was calculated using the equation proposed by Brug et al. [46]:

$$
C_{\mathrm{dl}}=\left[Q\left(R_{\mathrm{s}}{ }^{-1}+R^{-1}\right)^{\mathrm{n}-1}\right]^{1 / \mathrm{n}}
$$




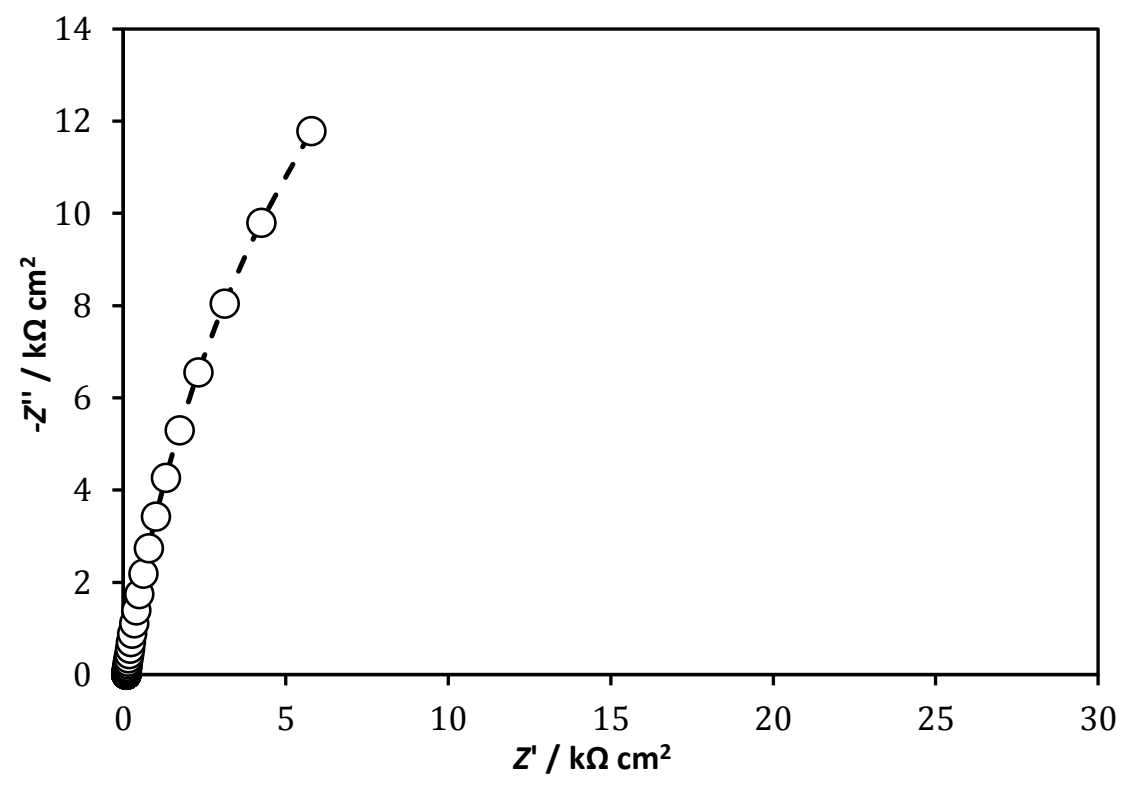

Figure 5. Nyquist plot of the $\mathrm{Ir}_{0.2}-\mathrm{Ni}_{0.8}$-oxide coating recorded in $0.16 \mathrm{M}$ saline phosphate buffer at electrode potential of -0.5 V. The dashed line represents the simulated spectra obtained using the equivalent electrical circuit model in Figure 1(a).

$C_{\mathrm{dl}} / \mathrm{mF} \mathrm{cm}^{-2}$ values for all coatings were calculated at $-0.5 \mathrm{~V}$ and the resulting values are presented in Figure 6. Analysis of the figure demonstrates that the $\operatorname{Ir}_{0.2}-\mathrm{Ni}_{08}$-oxide coating has a capacitance value of $2.09 \pm 0.25 \mathrm{mF} \mathrm{cm}^{-2}$. In contrast, iridium oxide (the state-of-the-art material for neural stimulation electrodes) has the value of $1.18 \pm 0.18 \mathrm{mF} \mathrm{cm}{ }^{-2}$, almost half of the value obtained for the $\mathrm{Ir}_{0.2}-\mathrm{Ni}_{08}$-oxide coating. Furthermore, the pure $\mathrm{Ni}$-oxide coating yielded a value of $0.88 \pm 0.16 \mathrm{mF} \mathrm{cm}^{-2}$, while the naked Ti substrate exhibited the lowest value of all substrates tested, at a value of $0.005 \pm 0.002 \mathrm{mF} \mathrm{cm}{ }^{-2}$. This reflects the superiority of the $\operatorname{Ir}_{0.2}-\mathrm{Ni}_{0.8}$-oxide coating in terms of double layer capacitance and thus, high charge storage capacity.

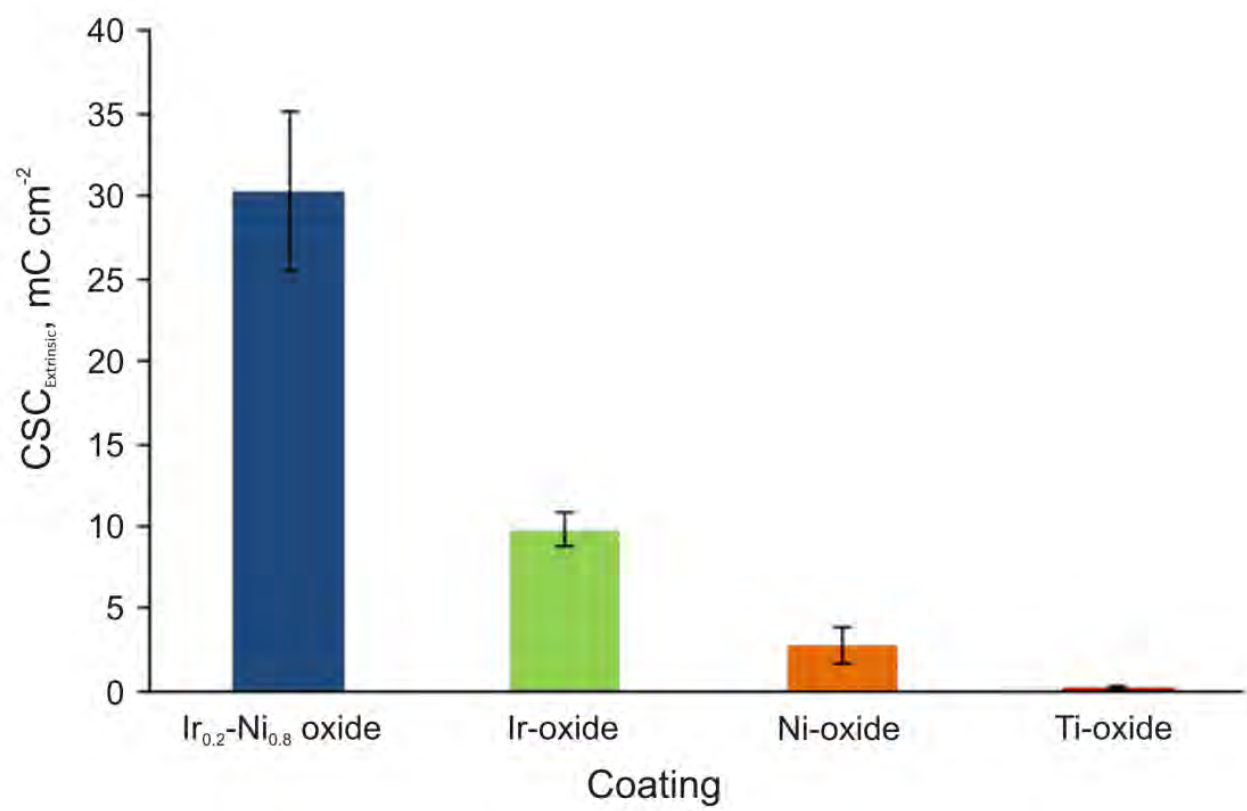

Figure 6. Dependence of the double-layer capacitance on the applied dc potential of various metal oxide coatings obtained by fitting EIS spectra. 
The next step in our analysis was to determine the intrinsic charge storage capacity ( $\mathrm{CSC}_{\text {Intrinsic }}$ ) of the coatings. Corresponding $\mathrm{CSC}_{\text {Intrinsic }}$ values were calculated by normalizing the extrinsic charge storage capacity ( $\mathrm{CSC}_{\text {Extrinsic }}$ ) values plotted in Figure 4 with respect to true electrochemical active surface (TEAS) area of the electrode coating. This was done by employing the following equation $[47,48]$ :

$$
\mathrm{CSC}_{\text {Intrinsic }}=\frac{\mathrm{CSC}_{\text {Extrinsic }} C_{\text {Theoritical }}}{C_{\mathrm{dl}}}
$$

where $C_{\text {Theoritical }} / 25 \mu \mathrm{F} \mathrm{cm}^{-2}$ represents the theoretical value of the double layer capacitance [13]. Calculated values of $\mathrm{CSC}_{\text {Intrinsic }}$ for all coatings are plotted in Figure 7.

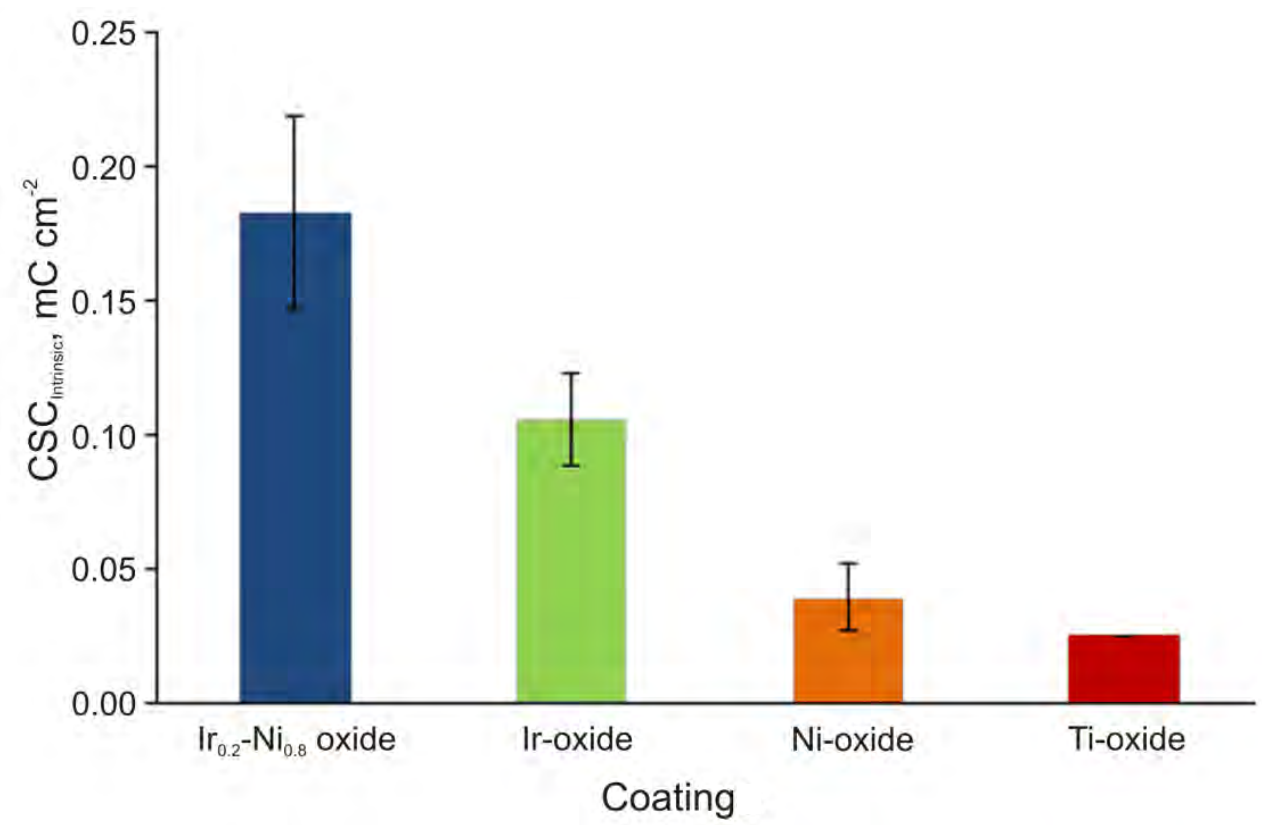

Figure 7. Total intrinsic charge storage capacity (CSC Intrinsic) of various metal oxide coatings obtained from $\mathrm{CVs}$ recorded in $0.16 \mathrm{M}$ saline phosphate buffer $\mathrm{pH}=7.4$, at a scan rate $\mathrm{sr}=100 \mathrm{mV} \mathrm{s}^{-1}$.

It is evident from Figure 7 that the $\mathrm{Ir}_{0.2}-\mathrm{Ni}_{0.8}$ oxide bimetallic coating has the highest intrinsic charge storage capacity as compared to other oxide coatings. Lower $\mathrm{CSC}_{\text {Intrinsic }}$ values indicate that large electrode sizes would be required in neural applications to deliver the required amount of charge. The high intrinsic CSC ability of the Ir-Ni composite proves that it has potential to be a useful material in the effort of neural electrode miniaturization, while still providing the charge necessary for successful stimulation.

\section{Conclusions}

In this study, the electrochemical properties of $\mathrm{Ir}$-, $\mathrm{Ni}$ - and $\mathrm{Ir}_{0.2}-\mathrm{Ni}_{0.8}$-oxide coatings formed on a Ti substrate were investigated in $0.16 \mathrm{M} \mathrm{NaCl}$ phosphate buffered solution, at $\mathrm{pH}$ of 7.4 , for the purpose of possible application of the materials in the technology of stimulating neural electrodes.

SEM results showed contrast between the stable, rough surface of the $\operatorname{Ir}_{0.2}-\mathrm{Ni}_{0.8}$ oxide coating and the $\mathrm{Ni}$ - and Ir-oxide coatings, which displayed the undesirable characteristic of slight cracking. In addition, it was also determined that the $\mathrm{Ir}_{0.2}-\mathrm{Ni}_{0.8}$-oxide coating had the highest charge storage capacity (CSC) both intrinsically and extrinsically. The $\operatorname{Ir}_{0.2}-\mathrm{Ni}_{0.8}$-oxide coating's extrinsic CSC of $30 \mathrm{mC} \mathrm{cm}^{-2}$ proved to be higher than the CSC offered by the current state-of-the-art neural 
stimulating electrode, Ir-oxide. EIS results also demonstrated that the $\operatorname{Ir}_{0.2}-\mathrm{Ni}_{0.8}$-oxide coating was optimal, achieving the largest capacitance (lowest impedance) value.

This novel bimetallic Ir-Ni-oxide coating serves as an extremely promising alternative to currently used pure Ir-oxide, Pt, Au and carbon-based stimulating electrodes. In-vivo investigations are now solicited to further determine biocompatibility and feasibility for use as a neural stimulating electrode in the various biomedical applications.

Acknowledgements: The authors would like to acknowledge the Natural Science and Engineering Research Council of Canada for providing the support for this research.

\section{References}

[1] S. Miocinovic, S. Somayajula, S. Chitnis, J.L. Vitek, JAMA Neurology 70 (2) (2013) 163-171

[2] J. L. Collinger, S. Foldes, T.M. Bruns, B. Wodlinger, R. Gaunt, D. J. Weber, Journal of Spinal Cord Medicine 36 (4) (2013) 258-172

[3] W. D. Memberg, K. H. Polasek, R. L. Hart, A. M. Bryden, K. L. Kilgore, G. A. Nemunaitis, H. A. Hoyen, M. W. Keith, R. F. Kirsch, Archives of Physical Medicine and Rehabiition 95 (6) (2014) 1201-1211

[4] B. M. Doucet, A. Lam, L. Griffin, Yale Journal of Bioogy \& Medicine 85 (2) (2012) 201-215

[5] L. R. Sheffler, J. Chae, Physical Medicines \& Rehabilition Clinics of North America 24 (2) (2013) 305-323

[6] D. Terzic, A. Abosch, Journal of Neurosurgical Sciences 56 (4) (2012) 267-277

[7] S.F Cogan, Annual Review of Biomedical Engineering 10 (1) (2008) 275-309

[8] R. Fröhlich, A. Rzany, J. Riedmüller, A. Bolz, M. Schaldach, Journal of Materials Science: Materials in Medicine 7 (7) (1996) 393-397

[9] Y. Lu, T. Wang, Z. Cai, Y. Cao, H. Yang, Y. Y. Duan, Sensors and Actuators B: Chemical 137 (1) (2009) 334-339

[10] T.M. Silva, J. Rito, M.G.S. Ferreira, I. Fonseca, K. Watkins, Journal of Materials Science: Materials in Medicine 7 (5) (1996) 261-264

[11] P.R. Troyk, S.F. Cogan, Neural Engineering, B. He, Ed (s)., Springer US, Chicago, USA, 2005, p. $1-48$

[12] Y. Xie, L. Zhou, C. Huang, H. Huang, J. Lu, Electrochimica Acta 53 (10) (2008) 3643-3649

[13] D. R. Merrill, M. Bikson, J. G. R. Jefferys, Journal of Neuroscience Methods 141 (2) (2005) 171-198

[14] Biomaterials, http://wikisites.mcgill.ca/bme501/images/a/a3/Class_Juncker_part1_071010.pdf (October 21, 2010)

[15] L. S. Robblee, M. Randolph, (EIC Laboratories, Inc. ), US4677989, (1987)

[16] T. L. Rose, L. S. Robblee, IEEE Transactions on Biomedical Engineering 37 (11) (1990) 11181120

[17] Y. Lu, Z. Cai, Y. Cao, H. Yang, Y.Y. Duan, Electrochemistry Communications 10 (5) (2008) 778782

[18] Y. Xie, D. Fu, Materials Chemistry and Physics 122 (1) (2010) 23-29

[19] M. Vuković, D. Marijan, D. Čukman, P. Pervan, M. Milun, Journal of Materials Science 34 (4) (1999) 869-874

[20] M.P. Neupane, I.S. Park, S.J. Lee, K.A. Kim, M.H. Lee, T.S. Bae, International Journal of Electrochemical Science 4 (2) (2009) 197-207

[21] I.-S. Lee, C.-N. Whang, J.-C. Park, D.-H. Lee, W.-S. Seo, Biomaterials 24 (13) (2003) 2225-2231

[22] K. Wang, H.A. Fishman, H. Dai, J.S. Harris, Nano Letters 6 (9) (2006) 2043-2048

[23] S. F. Cogan, A. A. Guzelian, W. F. Agnew, T. G. H. Yuen, D. B. McCreery, Journal of Neuroscience Methods 137 (2) (2004) 141-150 
[24] T. M. Silva, J. E. Rito, A. M. P. Simões, M. G. S. Ferreira, M. da Cunha Belo, K. G. Watkins, Electrochimica Acta 43(1-2) (1998) 203-211

[25] T. Arikawa, Y. Takasu, Y. Murakami, K. Asakura, Y. Iwasawa, The Journal of Physical Chemistry B 102 (19) (1998) 3736-3741

[26] V. V. Gorodetskii, V. A. Neburchilov, Russian Journal of Electrochemistry 39 (10) (2003) 1111-1115

[27] J. Kristóf, J. Liszi, P. Szabó, A. Barbieri, A. de Battisti, Journal of Applied Electrochemistry 23 (6) (1993) 615-624

[28] L. K. Xu, J. D. Scantlebury, Corrosion Science 45 (12) (2003) 2729-2740

[29] I.-H. Kim, J.-H. Kim, K.-B. Kim, Electrochemical and Solid-State Letters 8 (7) (2005) A369-A372

[30] V. Srinivasan, J. W. Weidner, Journal of the Electrochemical Society 147 (3) (2000) 880-885

[31] I. S. P. Madhav Prasad Neupane, Sook Jeong Lee, Kyoung A Kim, Min Ho Lee, Tae Sung Bae, International Journal of Electrochemical Science (4) (2009) $197-207$

[32] L. S. Robblee, (EIC Laboratories, Inc.), US4717581, (1988)

[33] S. H. Bonilla, C.F. Zinola, Electrochimica Acta 43 (3-4) (1998) 423-426

[34] P. Fernandez-Ibañez, S. Malato, O. Enea, Catalysis Today 54 (2-3) (1999) 329-339

[35] J. M. Hu, Acta Metallurgica Sinica 13 (3) (2000) 849

[36] S. Barison, S. Daolio, M. Fabrizio, A. De Battisti, Rapid Communications in Mass Spectrometry 18 (3) (2004) 278-284

[37] A. De Battisti, G. Lodi, L. Nanni, G. Battaglin, A. Benedetti, Canadian Journal of Chemistry 75 (11) (1997) 1759-1765

[38] S. Barison, S. Daolio, M. Fabrizio, A. D. Battisti, Rapid Communications in Mass Spectrometry 18 (3) (2004) 278-284

[39] G. J. Brug, A. L. G. van den Eeden, M. Sluyters-Rehbach, J. H. Sluyters, Journal of Electroanalytical Chemistry and Interfacial Electrochemistry 176 (1-2) (1984) 275-295

[40] I. S. Lee, C. N. Whang, K. Choi, M. S. Choo, Y. H. Lee, Biomaterials 23 (11) (2002) 2375-2380

[41] A. Armutlulu, J.K. Kim, M. Kim, S. A. B. Allen, M. G. Allen, Transducers and Eurosensors XXVII: The 17th International Conference on Solid-State Sensors, Actuators and Microsystems, Nickel-oxide-based supercapacitors with high aspect ratio concentric cylindrical electrodes, Barcelona, Spain, 2013, p. 1480

[42] K. R. Prasad, N. Miura, Applied Physics Letters 85 (18) (2004) 4199-4201

[43] A. K. K. Kyaw, H. Tantang, T. Wu, L. Ke, C. Peh, Z. H. Huang, X. T. Zeng, H. V. Demir, Q. Zhang, X. W. Sun, Applied Physics Letters 99 (2) (2011) 1107-1-1107-3

[44] N. Ullah, S. Omanovic, Journal of Surface and Coatings Technology (2014) p. submitted

[45] B. A. Boukamp, in Equivalent Circuit Users manual, Report CT88/265/128, University of Twente, Department of Chemical Technology, The Netherlands, 1989

[46] G. J. Brug, A. L. G. Van Den Eeden, M. Sluyters-Rehbach, J. H. Sluyters, Journal of Electroanalytical Chemistry 176 (1-2) (1984) 275-295

[47] D. Profeti, T. A. F. Lassali, P. Olivi, Journal of Applied Electrochemistry 36 (8) (2006) 83-888

[48] S. Trasatti, O. A. Petrii, Journal of Electroanalytical Chemistry 327 (1-2) (1992) 353-376

(C) 2014 by the authors; licensee IAPC, Zagreb, Croatia. This article is an open-access article distributed under the terms and conditions of the Creative Commons Attribution license (http://creativecommons.org/licenses/by/3.0/) (cc) Br 